tem sido atribuído à ação do veneno sobre o sistema nervoso simpático com liberação maciça de catecolaminas e/ou à ação direta do veneno sobre os cardiomiócitos, o que levaria a um quadro reversível denominado "cardiomiopatia escorpiônica". O objetivo do presente estudo foi avaliar as alterações clínicas e, com maior ênfase, os distúrbios cardiopulmonares produzidos no envenenamento causado pelo escorpião $T$. serrulatus $\mathrm{em}$ cães. Para tanto foram utilizados doze cães sem raça definida, nove fêmeas e três machos, com peso médio de $10 \mathrm{~kg}$. Estes càes foram subdivididos em dois grupos, sendo que os càes do Grupo $1(\mathrm{G} 1)$ foram inoculados com $0,25 \mathrm{mg} / \mathrm{kg}$ de toxina escorpiônica (cedida pelo Instituto Butantan) de T. serrulatus por via subcutânea e os animais do Grupo 2 (G2) receberam dose de $0,4 \mathrm{mg} /$ animal, dose esta que simularia um envenenamento natural. Estes cães foram considerados controles de si próprios e foram avaliados em cinco momentos distintos: T0-pré-envenenamento, T1-1 h pós-envenenamento (PE), T2-6 h PE, T3-24 h PE e T4$72 \mathrm{~h}$ PE. Em todos os momentos foi realizado exame físico para a obtenção de temperatura corpórea, frequências cardiaca e respiratória, tempo de preenchimento capilar e sinais clínicos. Nos momentos T0, T2, T3 e T4 foram realizados hemograma e determinação das concentrações séricas da isoenzima miocárdio-específica CK-MB, análise radiológica de tórax, exame eletrocardiográfico, avaliação ecocardiográfica e mensuração da pressão arterial sistêmica. Os resultados foram discutidos a $5 \%$ de significância $(p<0,05)$, sendo os dados quantitativos submetidos à análise de variância e os dados qualitativos submetidos ao teste do Q-quadrado. A ocorrência dos sinais clínicos concentrou-se nas primeiras 24 h pósenvenenamento e foram mais graves em G1. O sinal clínico mais importante em ambos os grupos estudados foi dor no local da inoculação do veneno, acompanhado de vômitos, diarréia, sialorréia, prostração e espirros. $O$ aumento da frequência cardíaca $(\mathrm{p}>0,05)$ ocorreu nos momentos T2 e T3 do G1, sendo que um dos animais deste grupo desenvolveu sopro apical sistólico em T2. O aumento da contagem do número de hemácias foi estatisticamente significativo em G1 e no momento T2, o que denota a desidratação ocorrida neste momento $\mathrm{e}$ a atividade hemolitica do veneno; $\mathrm{e}$ também foram observados a leucocitose por neutrofilia e linfopenia, caracterizando leucograma de estresse e o aumento da atividade sérica de CK$\mathrm{MB}$, o que revela dano miocárdico. As análises radiográficas demonstraram opacificação intersticial difusa em dois animais de G1 nos momentos T2 e T3. Os exames ecocardiográficos e a pressão arterial sistêmica mantiveram-se normais em ambos os grupos no decorrer dos momentos estudados. Foram ainda resultados de significância estatística as alterações eletrocardiográficas que incluíram inversão da polaridade da onda $\mathrm{T} \mathrm{e} / \mathrm{ou}$ aumento da sua amplitude em T2 e o aumento da amplitude das ondas P e R também em T2, alterações estas que caracterizam mais uma vez a ocorrência de injúria miocárdica nos animais do G1, principalmente. Os resultados, portanto, indicam que a gravidade dos sinais clínicos no envenenamento escorpiônico em càes relaciona-se diretamente à dose de peçonha inoculada. Doses mais elevadas são capazes de gerar agressão cardíaca e doses menores, que simulariam o envenenamento natural, causam quadro de envenenamento leve. Sendo assim, o veneno de escorpiào T. serrulatus pode ser utilizado como indutor experimental de lesão cardíaca em cães.

\title{
103 - Rim policístico congênito em Lhasa Apso
}

Rins policísticos são geralmente bilaterais e possuem relatos em gatos Persa, cães da raça Bull Terrier e West Highland White Terrier. O Lhasa Apso, juntamente com os cães da raça Shith Tzu, são descritos na literatura como predispostos a displasia renal congênita. Estes casos congênitos levam a sintomatologia de uma insuficiência renal crônica e apresentam um prognóstico ruim. Um animal da espécie canina, Lhasa Apso, fêmea de 5 meses de idade foi atendido em uma clínica veterinária privada com o histórico clínico de hiporexia, apatia e emagrecimento progressivo há aproximadamente dois meses. Quando questionado, o proprietário também passou a observar poliúria e polidipsia. Ao exame fisico o animal 
apresentava abdome distendido, mucosas hipocoradas, desidratação leve e caquexia, e nenhuma outra alteração referente a linfonodos, auscultação cárdio-pulmonar ou temperatura corpórea. Exames séricos apresentaram aumento significativo de uréia e creatinina, e um ultra-som abdominal revelou rins policísticos. $\mathrm{O}$ animal recebeu tratamento suporte com fluidoterapia e indicaçào de uma dieta terapêutica para nefropatas. Com a evoluçào do quadro e conseqüente piora do estado geral do animal, foram solicitados novos exames hematológicos que indicaram uma hipoproteinemia, anemia normocítica normocrômica e aumento dos níveis de uréia e creatinina em relação aos anteriores realizados. Os níveis séricos de sódio, potássio, cálcio e fósforo apresentavam-se dentro dos valores da normalidade. Um novo exame ultrasonográfico foi realizado no prazo de 20 dias após o primeiro, e o laudo apresentou uma diminuição da silhueta renal $\mathrm{e}$ aumento do tamanho dos cistos em parênquima renal direito e esquerdo. Um exame radiográfico do crânio revelou início de hiperparatireoidismo secundário renal. Após um mês do diagnóstico da doença renal polićstica o animal foi eutaniziado devido a sérias alterações neurológicas, e o exame necroscópico não foi autorizado pelo proprietário do animal. 